\title{
Percepción del espacio y APROPIACIÓN DEL TERRITORIO ENTRE LOS AYMARA DE ISLUGA
}

Juan Angel Aedo G. ${ }^{1}$

\begin{abstract}
Resumen
Bajo una perspectiva etnológica y geográfica se estudian algunos principios de la percepción del espacio y de la apropiación social del territorio, tomando el caso de Isluga. Por consiguiente, la escala de observación se situó al nivel de la experiencia de los actores sociales.

Nuestro objetivo apunta a develar algunas de las implicaciones intelectuales y prácticas de la producción social de la localidad, explorando cuatro factores: 1) La reconstrucción del lugar; 2) Los dispositivos de constitución ontológica del paisaje; 3) El problema

del centro; 4) Los elementos de morfología social. Se analiza la

manera en que se componen distintas escalas de apropiación del territorio y se observa cómo sobre la base de estos ejes se construye la geografía social de los aymara de Isluga.
\end{abstract}

Palabras claves: percepción del espacio - apropiación del territorio morfología social - Isluga - aymara.

\footnotetext{
Abstract

An ethnological and geographical perspective helps this paper study a few principles of spatial perception and of the social appropriation of territory, in this case the village of Isluga, from where our scale of observation concentrated on the experience of different social actors. This study aims to show the implications - both practical and intellectual- of the social production of locality, through the exploration of: 1) The reconstruction of the place; 2 ) The ontological devices constituting the landscape; 3 ) The problem of the center; and 4) The social morphology. Considering the different scales of territorial appropriation involved, the paper finally reflects upon the way Isluga inhabitants construct their social geography.

Key words: spatial perception - territorial appropriation - social morphology - Isluga - Aymara.
}

Recibido: agosto 2007. Aceptado: junio 2008.
"A recorrer me dediqué esta tarde, las solitarias calles de mi aldea acompañado por el buen crepúsculo que es el único amigo que me queda.

(...) Nada ha cambiado, ni sus casas blancas ni sus viejos portones de madera. Todo está en su lugar; las golondrinas en la torre más alta de la iglesia; el caracol en el jardín;y el musgo en las húmedas manos de las piedras. No se puede dudar, este es el reino del cielo azuly de las hojas secas en donde todo y cada cosa tiene su singular y plácida leyenda

(...) ¿Cuánto tiempo ha pasado desde entonces? No podría decirlo con certeza; todo está igual, seguramente, el vino y el ruiseñor encima de la mesa, mis hermanos menores a esta hora deben venir de vuelta de la escuela: isólo que el tiempo lo ha borrado todo como una blanca tempestad de arena!" Hay un día feliz (Parra 1997 [1954]).

\section{* INTROdUCCIÓN}

La indagación de las formas de construcción y de apropiación social del espacio lleva al investigador a enfrentar varios fenómenos y a examinar diversas nociones. Así, dos campos temáticos se revelan

\footnotetext{
${ }^{1}$ École des Hautes Études en Sciences Sociales. 18, rue des Vignerons, Vincennes, 94300, FRANCIA. Email : angeaedo@ehess.fr
} 
particularmente significativos para este análisis; por un lado, el que concierne a los elementos que participan en la producción social de la localidad, y por otro, el que se refiere a las modalidades sociales de los desplazamientos sobre un espacio dado. Del primer ámbito se desprenden algunas nociones preciadas por la antropología como aquellas de terreno y territorio. La segunda temática se articula en torno al movimiento y conduce a identificar algunos aspectos que orientan la acción, como los marcadores territoriales y las nociones a la vez tan importantes y problemáticas de centro y frontera. Sin ignorar los flujos de los mundos sociales contemporáneos, decidimos situar el punto de partida de esta exploración en un terreno específico. Este procedimiento se basa en la voluntad de conceder el lugar indispensable a las configuraciones estudiadas, aquella de los actores, de las situaciones relacionales y de los enunciados discursivos. Lo que nos anima es la preocupación de reflexionar en otros términos que los de una generalización implícita; nos interesa favorecer las experiencias de los actores para buscar reconstruir los contextos que le dan sentido y forma a dichas vivencias. De esta manera, en las páginas que siguen se presentan datos registrados en terreno con el fin de reconstruir un "lugar" en tanto que sujeto y objeto de la investigación. La escala reducida e intensiva de este estudio apunta a comprender mejor la interrelación de las lógicas sociales y a conjurar la propensión del investigador a reificar las categorías para pensar las relaciones sociales.

Apoyándonos en las pautas metodológicas presentadas por Marcus $(1998,2002)$, buscamos hacer una etnografía cuidadosa en seguir los desplazamientos y las reflexiones de la población. En contra de la figura cándida del indígena asociado a la exploración de tierras lejanas, trabajamos para devenir colaboradores de sujetos que tienen sus propios modos de análisis y de descripción etnográfica. Por lo demás, no permanecimos sólo dentro de los límites físicos de la localidad de Isluga. Las circunstancias temporales y el lugar donde nos situamos dan cuenta de una fracción del fenómeno a examinar. De ahí que consideramos necesario conducir una etnografía sensible a los cambios de las magnitudes espaciales y temporales. Cuando se requirió, seguimos los largos recorridos por los mundos rural y urbano efectuados por las familias que tuvieron la generosidad de acogernos en sus espacios de vida cotidiana. ${ }^{2}$

\section{* Hacia la reconstrucción de un lugar: IsLUGA}

Isluga hace alusión en primer término a una localidad del altiplano chileno que pertenece a la región de Tarapacá. Sus habitantes forman parte de un extenso y heterogéneo complejo cultural de pueblos de los Andes Centro Sur, que en el transcurso de la historia han recibido influencias de diversos grupos aymarófonos, así como de sociedades que hablaban otras lenguas como el quechua, el puquina, el kunza y el uruquilla. ${ }^{3}$ El conjunto heterogéneo de grupos indígenas del que formaba parte el territorio de Isluga era conocido bajo el nombre de Caranga. Esta era una antigua confederación de pueblos que hasta la mitad del siglo XVI se extendía del borde oriental del lago Poopó (al sur de Oruro) hasta los valles de la vertiente occidental de los Andes. ${ }^{4}$ Las grandes transformaciones socioeconómicas y demográficas que vinieron con el fin del siglo XVI impactaron la zona que ocupa Isluga, realzando el estatus fronterizo que ya tenía por su emplazamiento ecológico. Estas tierras tendieron a jugar un rol ambiguo característico de las zonas de frontera, tanto bajo la colonia española como durante la formación de los Estados nacionales en los inicios del siglo XIX. Bajo la política de "reducción de indios a pueblos" ejecutada por la Corona española en sus colonias de América, la zona de la cuenca del río Isluga se emplazó en los confines de los centros

\footnotetext{
2 El trabajo de terreno sobre el que se apoya este artículo fue efectuado en dos periodos: 1) diciembre de 2005 y enero y febrero de 2006; 2) julio, agosto y septiembre de 2006.

3 Torero (2002), apoyándose en la información del Primer Sínodo del Obispado de Arequipa efectuado en 1638, afirma que el puquina era hacia la mitad del siglo XVII una lengua hablada en las vertientes occidentales de los Andes, y probablemente, hasta la costa del Pacífico. Por otra parte, se constata que la lengua uruquilla, que según este autor se distinguía claramente del puquina, se hablaba en el sur del lago Titicaca (en la aldea de Cepia o Zepita), alrededor del lago Poopó (Aullagas) y en los alrededores de la Puna Salada de Lípez, al suroeste de Bolivia.

4 Para un examen de la documentación del pasado prehispánico de los Carangas, ver Rivière (1982).
} 
administrativos de aquel entonces. Lejos del núcleo colonial del Corregimiento Caranga y distante también de las tierras occidentales consideradas de interés productivo por las autoridades hispanas, las cuales no sobrepasaron por lo común los 2000 m.snm (González 2002, cit. en Bengoa 2004: 98-99). Una línea definida en 1578 demarcaba al Corregimiento de Caranga del Corregimiento de Arica; esta línea que pasaba por la cuenca del río Isluga coincide con la frontera actual entre Chile y Bolivia. ${ }^{5}$

El dominio colonial español ejerció un poderoso efecto sobre los órdenes socioespaciales preexistentes. Se ha abierto un amplio campo de investigación y debate sobre las dinámicas de permanencia y cambio de las sociedades de los Andes Centrales (p.e., Abercrombie 1990, 1998; Wachtel 1990; Urton (1993), pero no nos detendremos en esta problemática, ya que la inmensidad de información histórica todavía sin trabajar a la luz de las nuevas corrientes de la antropología y de la historia podría hacernos perder de vista el propósito de este estudio. Para evitar la reificación del término "aymara" bastará provisionalmente con reconocer que durante la Colonia los desplazamientos de las poblaciones fueron intensos, por lo que también fueron intensos los intercambios lingüísticos, en especial entre el castellano, el latín y varias lenguas indígenas. Este proceso de interacción, alteración y mutación de los grupos socioculturales explica, por ejemplo, la existencia de muchos préstamos lingüísticos del castellano al aymara hablado en el altiplano de Tarapacá. Son bastantes las evidencias de que en este período las poblaciones de los Andes Centro-Sur sufrieron una intensa reconformación sociocultural. No tiene sentido hablar de lo aymara como un tipo de población pura, por lo tanto no buscaremos los supuestos casos "originales", que constituyen a nuestro juicio fantasías antropológicas cada vez más rentables para las empresas de turismo étnico que invaden los más remotos lugares del mundo. Plantear la investigación en dichos términos supondría negar desde el inicio el carácter histórico y creativo de las agrupaciones sociales que habitan los Andes Centro Sur. La palabra aymara es utilizada en

5 Amojonamiento, 1878 (Durston e Hidalgo 2004: 488). esta indagación para facilitar la descripción de una población contemporánea de la Región de Tarapacá que se autocalifica como aymara a un nivel general, es decir, cuando se trata, por ejemplo, de las relaciones con el Estado chileno y con organizaciones no gubernamentales nacionales y extranjeras. En el resto de los casos preferimos emplear la manera en que se refieren a sí mismos nuestros interlocutores, la mayoría de las veces simplemente como habitantes de Isluga.

Durante los recorridos a pie por diferentes unidades ambientales de la comunidad de Isluga se descubren bofedales y lagunas rodeadas por sedimentos salinos que atestiguan el pasado lacustre de algunos de estos territorios. En términos generales, estas tierras constituyen el límite occidental de una unidad geomorfológica más amplia, el altiplano de los Andes Centro-Sur, cuya mayor parte se encuentra hoy en día en territorio boliviano. El clima dominante es el de Estepa de Altura (BSh), caracterizado por precipitaciones de verano y por una marcada oscilación térmica diaria (desde $-5^{\circ} \mathrm{C}$ durante la noche y hasta $25^{\circ} \mathrm{C}$ en el día). ${ }^{6} \mathrm{La}$ altitud promedio es de $4000 \mathrm{~m} . \mathrm{snm}$ y las lluvias estivales disminuyen a medida que se viaja hacia el sur. Las precipitaciones más abundantes caen desde diciembre hasta marzo, favoreciendo el crecimiento de un tipo de pasto grueso que sirve para alimentar al ganado camélido y ovino. Los cursos de agua en Isluga poseen pendientes más suaves que aquellos que corren hacia el Pacífico, característica que ayuda a la formación de humedales o bofedales que son suelos compuestos por una importante masa compacta de materia orgánica en distintas fases de descomposición. Estas formaciones resultan fundamentales para que en Isluga pueda desarrollarse la ganadería de camélidos (ver Gundermann 1984). Desde un punto de vista general la zona que ocupa Isluga posee las características ecológicas típicas de la estepa altoandina (3500-5000 m.snm). Sin embargo, desde el punto de vista local, se divide y clasifica en función de criterios sociales, cosmológicos y ecológicos.

\footnotetext{
${ }^{6}$ Según la clasificación de los tipos climáticos de Köeppen (Núñez et al. 1988).
} 
El término aymara marka es utilizado de manera genérica por los islugueños para referirse tanto a este pueblo en su conjunto, como en particular a su centro ceremonial. Los etnógrafos han registrado esta palabra en distintos contextos sociales y en la mayoría de los casos parece funcionar como una etnocategoría de orden general para designar a los pueblos andinos. Por otra parte, se encuentra esta expresión en las fuentes coloniales para indicar una forma de organización socioespacial de los pueblos indígenas que habitaban los Andes Centrales (Bertonio 1984 [1616]: 217; Rivière 1982; Wachtel 1990; Van Kessel 1992; Abercrombie 1998; Harris 2000; Bouté 2003). Igualmente, a partir de este término, se forma la expresión marka masi que alude a la pertenencia de los individuos a la comunidad de Isluga en su totalidad.

Nos limitaremos por el momento a indicar que la organización del espacio en Isluga yace en la definición de un centro denominado aka que comprende el pueblo y los lugares sagrados: sobre todo la iglesia y los ancestros deificados que habitan al interior de las formas singulares del paisaje circundante. El término marka designa entonces, en sentido estricto, el pueblo $y$, por extensión, evoca el centro del espacio habitado. El centro ceremonial de Isluga, las estancias que rodean a esta localidad y la periferia "salvaje" (sallqa) forman idealmente un todo: el akapacha (el mundo nuestro) (ver Bertonio 1984 [1616]; Martínez 1976b; Van Kessel 1992, 1996). Resulta interesante observar que el término sallqa en un contexto profano, es decir, fuera de los relatos míticos y de los procesos rituales, se utiliza para designar a los impostores y charlatanes. Estos dos sentidos de sallqa comparten un mismo campo semántico, el cual remarca tanto la desconfianza que suscitan los espacios desconocidos e indómitos como los individuos que engañan a través de falsas apariencias.

\section{* Maneras de pensar el espacio}

Las palabras del epígrafe resuenan guiando esta tarea de reconstruir un lugar. La experiencia del poeta no es inaudita puesto que se refiere a aspectos muy generales que forman parte de prácticas socioespaciales comunes a los seres humanos. Pero no se trata simplemente de una evocación de orden general, porque dichas palabras nos sitúan precisamente dentro de la problemática de este trabajo: las propiedades de los lugares y sus dinámicas. Así, Isluga y sus contextos de vecindad tienen algo que decirnos con respecto "al espíritu" de los lugares, sobre el cual Parra (1997 [1954]) constataba que "todo y cada cosa tiene su singular y plácida leyenda". De tal suerte, las propiedades de los lugares vienen de las particularidades de sus emplazamientos, de sus relaciones de vecindad, de sus historicidades $y$, ciertamente, del punto de vista del observador. La confluencia de fenómenos diversos contribuye a conformar el espacio de Isluga y a conferirle su singularidad. Una búsqueda de las propiedades de los lugares no es anodina en la medida en que los atributos de las partes que componen Isluga pueden determinar - en condiciones precisas- la evolución de estos mismos lugares.

Otro aspecto de la composición del espacio en Isluga que debemos mencionar es la estrecha relación -a nivel de la lengua- que se puede constatar entre el contexto espacial y la orientación de las acciones. Un ejemplo de la orientación como una parte vinculada íntimamente con la formación del verbo es revelado por el hecho de que en aymara hay un derivativo especial, naqa, para indicar la acción sin dirección en el espacio, la cual se considera normalmente como involuntaria y de sentido difuso (England 1975: 129-130; Hardman 2001: 82). La dirección y la localización son dos fenómenos imbricados en la mayoría de los términos para indicar una acción. Este doble aspecto alimenta la percepción general de los lugares en tanto que partes de redes más vastas. Por consiguiente, bajo la perspectiva de los actores, Isluga no podría ser pensada sino como un espacio relacional, en donde sus interconexiones, su dinámica e incluso su estructura son sometidas a prueba de manera constante.

La intencionalidad equívoca de algunas acciones consideradas absurdas es a menudo marcada por la derivación verbal, naqa, de la cual se ha referido su función. En este contexto, es pertinente constatar la existencia de un sufijo verbalizable que es formalmente 
simétrico al de naqa y cuyo significado es totalmente inverso. Se trata de nuqa, el cual expresa la disposición de colocar los seres y las cosas en el espacio. Este último término que es diferente de naqa por un solo fonema, tiene una función que le es enteramente contraria, porque actúa para insertar las acciones dentro de un lugar determinado, constituyendo de este modo un factor importante para la generación de sentido. Por contraste a la confusión de las acciones no orientadas espacialmente que son señaladas por el sufijo naqa, los hechos indicados por nuqa implican un contexto espacial delimitado. Este fenómeno es bien ilustrado por la expresión ut.nuqa.ña (uta "casa" + nuqa), la cual indica la acción de establecerse en una casa. ${ }^{7}$

Se cometería un error al desconocer esta dimensión de la configuración del espacio. Estos elementos de la lengua, en apariencia intangibles, son fundamentales para la confección de los lugares. Ellos constituyen indicios de una clasificación dual inscrita al nivel de la formación del verbo. Más allá de la contemplación estática del mundo, esta constatación nos servirá para intentar profundizar la indagación de los fundamentos del espacio vivido.

Es necesario remarcar dos aspectos adicionales que participan en la construcción del espacio: la preocupación de los habitantes de Isluga para bien localizar los seres y las cosas, y la disposición inscrita en la lengua para pensar el tiempo bajo una dimensión espacial. Atendamos por el momento los aspectos indispensables para el análisis.

La inteligibilidad del mundo y la coordinación de las acciones para transformarlo comportan algunas operaciones espaciales que ponen en juego ciertas estrategias cognitivas que se encuentran en la configuración del espacio percibido, vivido y concebido. Esta utilización del espacio supone, no obstante, que se ocupen determinados instrumentos de orientación tales como los sufijos de localización. Sobre este plano la lengua aymara otorga una atención considerable, puesto que

\footnotetext{
7 Hardman (2001: 78) proporciona otros ejemplos: “Apa.ña : carry + nuqa $=$ ap.nuqa.ña $:$ put down".
}

ella posee varios sufijos para indicar el sitio preciso donde tiene lugar una acción. Deesta forma se observa que "wi" señala el lugar o la ocasión de una acción, por ejemplo en el enunciado: ut.ja.wi.sa.x, es decir, "el lugar donde habitamos" (uta: casa/-ja-: verbalizador/-su: posesivo/-xa: sufijo ocasional). ${ }^{8}$

Cuando un fenómeno no es localizable en el espacio y en el tiempo, este deviene en un fenómeno difícilmente inteligible. Es por ello que la localización constituye en este caso un esfuerzo intelectual para reducir la incertidumbre. De esta manera, la utilización de dos clases de sufijos: "wja" y "jita" ilustra esta determinación para precisar la localización de las acciones. Así, "wja" (lugar) se utiliza habitualmente para situar un punto del espacio, por ejemplo, en la expresión "aka. wja.n.k.t.wa: estoy aquí en este lugar". Además, se encuentra a menudo este sufijo precediendo a otro, el de "jita", con el fin de reducir al máximo las ambigüedades de la ubicación. De este modo, "jita" indica el lugar exacto donde se desarrolla una acción; de suerte que se podrá hacer hincapié en la exactitud de un lugar diciendo "ajita.n: en este lugar preciso".?

Las interconexiones y determinaciones recíprocas de los seres requiere que se les dé un lugar preciso en el ordenamiento del cosmos, lo que a la vez les confiere una parte de sus propiedades intrínsecas. Es por ello que la deslocalización de los elementos posee un poder tan perturbador. De la misma forma, la sensación que comparten la mayoría de los ancianos de Isluga que conocemos, de no encontrarse en su lugar cuando prolongan demasiado sus estadías en las ciudades costeras va acompañada de la creencia de que este estado de ánimo puede conllevar la enfermedad e incluso la muerte. Es significativo que una de las preguntas que

\footnotetext{
${ }^{8}$ Ver por ejemplo el trabajo de Briggs (2001 [1988]) sobre la estructura del sistema nominal.

9 Ver Briggs (1975, cap. VIII, vol. 3) y Hardman (2001: 137). Cuando se introducen estos dos sufijos (wja y jita) dentro de un enunciado, se pueden formar otras expresiones tales como "chilla.wj.ita.n": "exactamente en la chilla del cuerpo humano" (en este caso, las dos "j" de los sufijos wja y jita se reducen a una sola). El término chilla indica un lugar del cuerpo humano situado entre las costillas y las caderas (Briggs 2001 [1988]: 201-202).
} 
se escucha con frecuencia en toda clase de circunstancia sea kawki, es decir ¿dónde?; como si la determinación del lugar de los elementos en el tiempo y en el espacio constituyera una condición sine qua non para la inteligibilidad de las cosas. ${ }^{10}$

Las percepciones del tiempo entre las "sociedades andinas" han despertado el interés de varios investigadores. El tema es extremadamente amplio para abordarlo plenamente aquí. En consecuencia, nos concentraremos en un aspecto preciso, aquel de la espacialización de los acontecimientos temporales. En efecto, las formas lingüísticas utilizadas para referirse a las acciones temporales llevan a percibir el tiempo como algo espacialmente situado. De esta manera, el futuro es colocado detrás del individuo que interactúa, razonándose aquí en términos espaciales en la medida en que se percibe al futuro ocupando una posición fuera del campo de visión ordinario. Por el contrario, el presente y el pasado componen una unidad situada delante del actor, la cual es de cierta forma visible por el hecho de ocupar un lugar alcanzable por la "mirada" del sujeto. A este respecto son particularmente ilustrativas las metáforas espaciales utilizadas en la vida cotidiana, por ejemplo: q'ipürkam "hasta un otro día" (hasta pronto), que según Hardman (2001: 6) se divide en q'ipa: "en la espalda de", (uru) "día" y (kama) "hasta".

Existe consenso entre los lingüistas sobre el hecho de que en la lengua aymara la localización espacial - particularmente el lugar y la orientación- se señala cuidadosamente por la estructura gramatical. Las grandes extensiones geográficas, especialmente la pampa semidesértica del altiplano, se perciben como espacios "recipientes" conteniendo propiedades que pueden encontrarse ora agotadas (ch'usa), ora plenas de vitalidad (phuq'a). ${ }^{12}$ No resulta al azar que en el juego de

10 Por ejemplo, "kawki.n.k.iri.ta.sa": "¿de dónde vienes?" o "kawk.sa.n.k.iri. ta.sa": “ide qué lugar vienes?” (Briggs 2001 [1988]: 187).

${ }^{11}$ Otros lingüistas han retomado este ejemplo con el fin de ilustrar la importancia de la dimensión espacial para pensar el tiempo (p.e., Martin et al. 2001: 19).

12 El sentido literal del término ch'usa es vacío. Otro adjetivo menos utilizado para referirse a este aspecto del paisaje es el de qarita (agotado, sin vigor). La locución phuq'a indica, en sentido estricto, aquello que está las analogías que recorren la percepción del mundo el término pampa sea empleado para designar otro tipo de "recipiente", esta vez no en el espacio geográfico, sino en el espacio textil. En particular, la parte del tejido que los habitantes de Isluga designan pampa recibe también el nombre de "cuerpo". Esta apelación es característica de las talegas o wayaja, de los jawayu o mantas y de las wak'a o fajas. El espacio específico atribuido a la pampa de los tejidos se encuentra circunscrito habitualmente por un segmento central (taypi) y por un borde (laka). Estas dos partes constitutivas de los tejidos poseen características técnicas e iconográficas singulares, lo que las diferencia del sector designado pampa. Al igual que la facultad de receptáculo que es una propiedad de las grandes extensiones planas, la pampa de los tejidos es percibida como un continente, como un cuerpo que sostiene el conjunto. ${ }^{13}$

\section{- Dispositivos De CONSTITUCIÓN ONTOLÓGICA DEL PAISAJE}

La proliferación de topónimos y las divisiones minuciosas de la superficie terrestre (uraqui) están vinculadas a la importancia de la localización geográfica como parte constitutiva del "tejido social". El término pampa designa, en un sentido amplio, a todo espacio elevado, plano y semiárido. El altiplano, que es un ejemplo, también se asocia de manera general a la sexualidad femenina. Por oposición, las cumbres de las montañas son lugares donde se acumulan fuerzas eminentemente masculinas. Uno de los paradigmas de la "sexualización" de las formas del paisaje físico se expresa a través de la pareja tutelar de las estancias: el mallku que es el dueño de las alturas andinas y su mujer t'alla, que habita las planicies del altiplano.

lleno; igualmente se utiliza el término chama (fuerza, vitalidad) para describir esta característica del espacio.

13 Los procesos de producción y de creación de los tejidos de Isluga han llamado la atención de diversos etnógrafos, entre ellos, Medvinski (1977), Cereceda (1978) y Gavilán y Ulloa (1992). Estos estudios concuerdan con nuestros datos etnográficos en lo que concierne a la permanencia del uso de la noción de pampa para identificar un espacio compositivo de los tejidos andinos. 
Las huellas de estas entidades se multiplican en el territorio de Isluga aprovechando las singularidades de la superficie terrestre. Las acciones de esta pareja no se reducen a intervenir sobre la formación del paisaje, ellas también operan sobre el curso del tiempo, marcando en particular la alternancia entre el día (uru) y la noche (aruma), así como el ritmo de las estaciones (jallu pacha, thaya pacha, juyphi pacha). ${ }^{14}$ Este dispositivo de sexualización de las formas del paisaje se encuentra en la mayoría de las regiones de los Andes. La energía fecundante que procede de la interacción -a varias escalas- de la pareja mallku/t'alla anima el mundo circundante y garantiza la continuidad vital, gracias a su intervención en favor de la reproducción del ecosistema. Dichas entidades anímicas se encuentran también en el origen de otros fenómenos cíclicos, tales como la variación de los medios de subsistencia, y el desarrollo adecuado del conjunto de los seres que habitan sus dominios. Desde este punto de vista, mallku y t'alla se convierten en los dueños absolutos del medio ambiente. En la medida en que estas deidades pertenecen a los espacios que ellas mismas confeccionan, deben también ocuparse de las relaciones que mantienen sus criaturas y velar por su reproducción. Al igual que como una pareja de pastores, mallku y t'alla extienden sobre Isluga el abrigo de su protección. Esta tarea los autoriza éticamente a disponer a su manera de los seres que ellos mantienen.

El poder fecundante de los "dueños" del paisaje se expande a través de las singularidades de la topografía. Dichos espacios individualizados poseen sus propias historias y ámbitos de actividad. La percepción de las formas y sustancias que componen el territorio es un factor que constituye la realidad sobre la cual actúan efectivamente los habitantes de Isluga. Es por esta razón que los intercambios entre los diferentes seres que ocupan las partes del territorio deben ser organizados por los islugueños, de manera que los recursos extraídos del medio ambiente puedan ser reintroducidos dentro

\footnotetext{
${ }^{14}$ Jallu pacha $=$ temporada de las lluvias (octubre-marzo); juyphi pacha = temporada de las heladas (abril-junio); thaya pacha = temporada del viento frío (julio-septiembre). El jallu pacha es también asociado al junt'u pacha o lupi pacha, es decir "la temporada cálida".
}

de un circuito generalizado de "fuerzas" (ch'ama). De esta manera, se observa en Isluga la tendencia a que el comienzo de un nuevo ciclo agropastoral sea acompañado por acciones de compensación contempladas a restablecer el orden de las cosas. Estas acciones se desarrollan -antes de todo- por medio de un "trabajo ritual" que compromete diversas escalas de la organización social, desde el hogar doméstico y la estancia hasta toda la comunidad de Isluga.

La localización vista desde las prácticas no se reduce en Isluga simplemente a la sujeción a un terreno específico, ella actúa también como un principio que organiza el movimiento. La movilidad conlleva la relación con los otros y, por consiguiente, somete la identidad Isluga a una prueba constante. El hecho de nacer en Isluga o de tener parientes dentro de este territorio constituye un factor importante de producción de sentido. La comunidad de Isluga participa como significante sociocultural en la confección de las identidades individuales de sus habitantes. La localización en tanto factor de identidad se manifiesta como organizador social que concede derechos y obligaciones. Los islugueños utilizan el término jausata para designar a los extranjeros que no pertenecen (por filiación o por alianza) a la comunidad, de este modo dichos individuos son desprovistos de identidad, e incluso son privados de un nombre que les permita actuar en los asuntos comunitarios. ${ }^{15} \mathrm{~A}$ través de este término, los habitantes de Isluga subrayan el aspecto faltante que procede del estatus social de "extranjeros", ya que jausata en sentido estricto indica la acción de llamar a alguien por su nombre. ${ }^{16}$ Aquí, el nombre constituye para los Isluga un signo ostensible de los lazos sociales con el territorio.

La identidad, para construirse se alimenta de referencias geográficas concretas extrayendo de las representaciones políticas y religiosas el material conceptual para

\footnotetext{
15 Se designa a las personas que no tienen ningún parentesco con los habitantes de Isluga bajo el término yaqa jaqe. Los extranjeros que proceden de territorios lejanos son llamados wasa jaqe.

${ }^{16}$ Bertonio (1984 [1612]: 125) registra (bajo el modelo de trascripción de su época) los términos emparentados de "hauifatha: llamar, decir que venga", "haifanitha: ir a llamar"; "haui: hola ven acá", "hauifma, vel hauifafma: yo te llamo".
} 
reforzarse. La casa familiar $(\text { uta })^{17}$ y la casa secundaria (jant'a), la cocina (phayawi), la estancia central (qutu qutu marka) y la estancia satélite (uta uta o utjäwi), el ayllu, la mitad (saya) y el conjunto de la comunidad de Isluga (marka masi), así como la municipalidad, la región y el Estado nación constituyen efectivamente un sistema de referencias identitarias que llevan al investigador a esbozar un juego de escalas comparadas. En esto consiste el reto que intentaremos enfrentar en las siguientes páginas. El camino elegido es el de una exploración etnográfica que intenta reconstruir las principales características de la geografía social de los habitantes de Isluga.

\section{• El problema del centro}

Las redes de correspondencias entre ámbitos aparentemente disímiles se expresan en Isluga no solamente a través del empleo del término pampa, el cual designa una porción fundamental de los espacios textil y geográfico. Así por ejemplo, taypi alude a la confluencia central de todo tipo de lugares. Los aymara de Isluga se refieren también a este pivote del espacio con el nombre de chuyma o chhima (corazón), con lo cual enfatizan su función de receptáculo de sentimientos y de productor de la "personalidad" de un lugar. ${ }^{18} \mathrm{El}$ tema de la producción del "espíritu" de un lugar no es desdeñable. Cuando los habitantes de Isluga hablan de los lugares "antiguos", como en el caso del cerro Pukar Qollu" ${ }^{19}$, no resulta extraño escuchar comentarios que aluden a la imprevisible personalidad de este sitio. Se dibuja, en consecuencia, un juego de correlaciones entre la concepción del corazón en tanto principio anímico, la facultad acumulativa de las potencialidades de este principio (chuyma) a través de la vejez de los espacios,

\footnotetext{
17 Utanaja es la forma plural del término uta.

18 Los datos etnográficos que disponemos de Isluga evidencian que los habitantes de la parte manqha saya utilizan con más frecuencia la locución chuyma, en cambio en las localidades del extremo occidente de araj saya, se escucha con mayor recurrencia la referencia a chhima como centro/corazón del espacio. Cabe señalar que Cereceda (1978) consigna el empleo de chhima para aludir a la banda central y "corazón" de las talegas de Isluga.

19 Espacio ceremonial con vestigios arqueológicos que se encuentra en las inmediaciones del pueblo de Isluga.
}

y la transformación en sabiduría de la concepción del centro/corazón. Este desplazamiento conceptual ilumina, en parte, el alcance de la expresión chuyma-ni, la cual se utiliza todavía entre los aymara de Isluga para referir a la vez al anciano y al sabio.

El corazón de un espacio (chuyma) constituye una entidad diferente del corazón orgánico, al cual los aymara de Isluga designan lluqu y que se localiza en las vísceras del cuerpo. La posición topológica de chuyma le permite actuar como bisagra entre los espacios interior y exterior, y frontera de los mundos visibles e invisibles. Igualmente, el centro/corazón constituye un principio del entendimiento, lo que fundamenta la sabiduría de los ancianos. Es por eso que se recurre a esta noción para calificar tanto la cordura como la pérdida del juicio de los individuos. Así por ejemplo, a través de la expresión chuyma-chasiña se designa el proceso de adquisición de entendimiento, y en un sentido contrario, chuyma-pisi enfatiza la falta de juicio de un individuo. Literalmente chuyma-pisi indica aquel que tiene poco corazón (pisi: poco, escaso; ver De Lucca 1982: 339). De ahí que la locura, entendida como el desorden del espíritu, no pueda situarse en la base de la construcción ontológica de un lugar. Por el contrario, las entidades causantes de locura, tales como el supay, los kukushi (condenados) ${ }^{20}$, las wak'a y los jintili (gentiles) $^{21}$ intervienen para subvertir el orden de los

\footnotetext{
20 Almas de difuntos que permanecen atrapadas entre el mundo de los vivos y el de los muertos. La acción de los condenados sobre la vida cotidiana es percibida como una fuerza que perturba el orden del mundo de los vivos. La principal causa para ser condenado es haber realizado en vida de una trasgresión social considerada grave, como por ejemplo, un incesto.

${ }^{21}$ Con el nombre genérico de "gentiles" se hace alusión a las entidades anímicas asociadas a los restos arqueológicos que simbolizan una humanidad anterior. Especialmente, los "gentiles" merodean las torres funerarias o chullpas. Los "gentiles" pueden ser una fuente de peligro, desventura y enfermedad, es por ello que la mayoría de los habitantes de Isluga evita aproximarse a estos lugares que sólo son accesibles a los "más fuertes" y ancianos de la comunidad. En particular se tiene mucho cuidado de no llevar a los niños a jugar cerca de las chullpas. Van Kessel registra igualmente esta noción entre los aymara, y agrega que en el caso de existir "un gentil muy bravo" que difunde muchos males, es posible realizar una operación para amortiguar los peligros: "si descansan tranquilos, si nadie se les acerca, ni los molesta, no pasa nada" (2001: 222).
} 


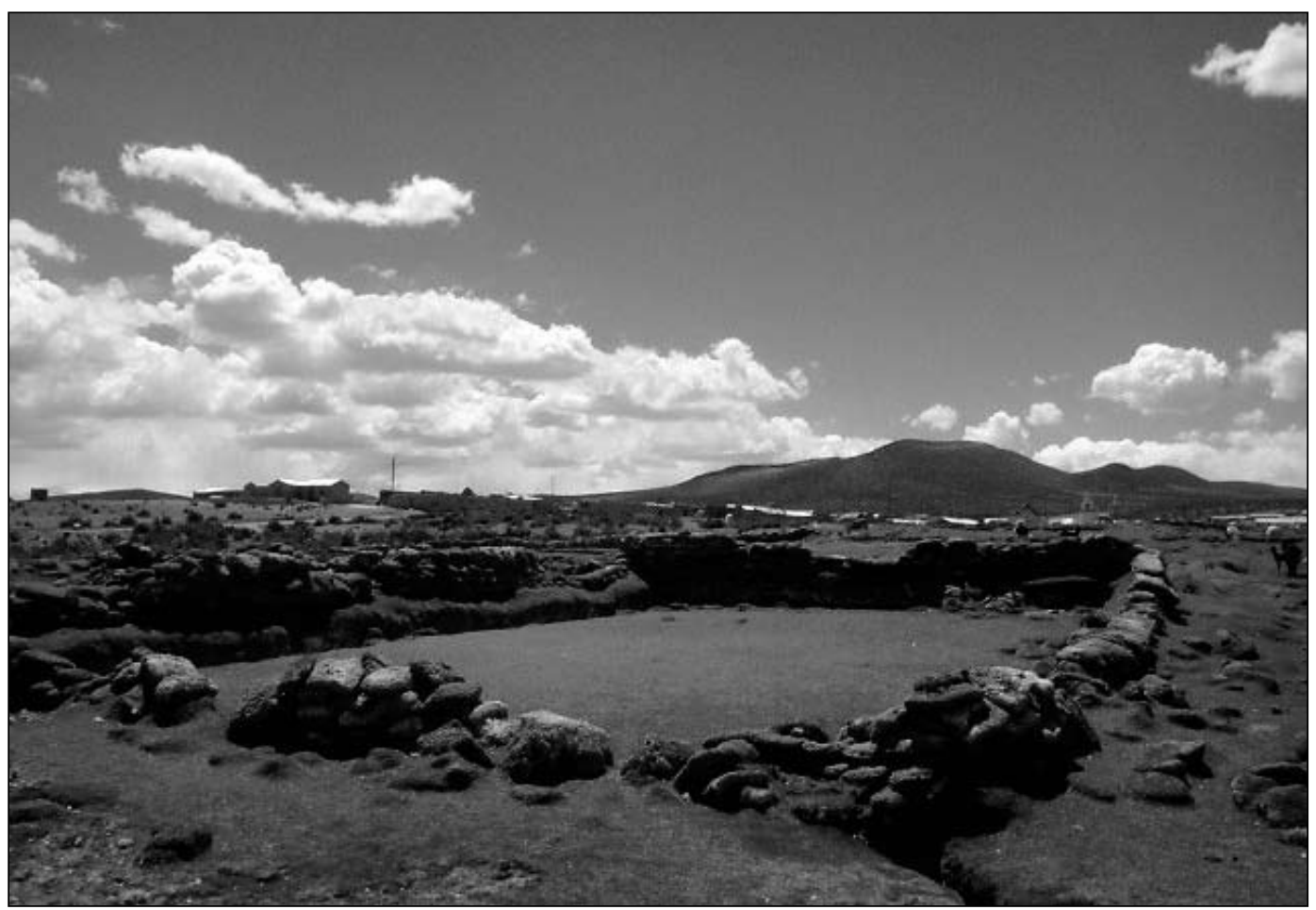

Figura 1. Vestigios de uno de los corrales "primigenios" del champial.

espacios y para desorientar a los sujetos. Se entiende en este contexto la razón de por qué la cordura, es decir el orden del espíritu, alimenta la noción de centro (taypil chuyma) y es uno de los soportes de la construcción de todo tipo de lugares.

Por otra parte, la palabra churu es empleada de forma genérica en Isluga para indicar la presencia de recintos rectangulares cerrados por muros de piedra de baja altura. Estos espacios son habitualmente lugares de trabajo, siendo destinados para corrales de camélidos $(u y u)^{22}$ y para el cultivo en chacras (yapu). Pero las implicaciones de este término no se agotan en el campo del quehacer ordinario, puesto que también la noción de churu es retomada por el lenguaje ritual para aludir a las chacras y corrales "originales" de Isluga que, según algunas glosas míticas, legó el primer cultivador y pastor de la comunidad a los islugueños. Algunos testimonios

\footnotetext{
22 Se escucha a veces la variante uyo entre los habitantes de las estancias más orientales de la mitad manqha saya. Cuando los habitantes de Isluga desean distinguir entre diferentes tipos de "corrales" utilizan el término kancha para señalar aquellos destinados a las llamas y alpacas, y uywij uyu para indicar los que se destinan a las ovejas.
}

y observaciones rituales nos llevan a pensar que dicho personaje se encuentra actualmente metamorfoseado en el uywiri de Pukar Qollu. Las relaciones que establecen los habitantes de Isluga con este héroe civilizador transformado en las principales montañas mallku de la región sugieren que este personaje continúa actuando como un pastor, pero esta vez como un pastor de todo lo existente. Hoy las trazas materiales de las chacras y de los corrales primigenios perduran en un espacio ubicado en el centro de la comunidad, en un terreno dejado cuidadosamente bajo un aspecto "agreste", el cual es popularmente conocido como el champial y cuyo nombre ritual es el de ch'alla churu (Figura 1).

Las características atípicas de este sector despertaron desde un inicio nuestra curiosidad. A pesar de aquello, durante mucho tiempo no recibimos información sobre este lugar. Todo parecía suceder como si el estado de abandono físico que le otorga el aspecto agreste al champial se reforzara por un clima de apatía generalizado que impide convertir a este sitio en un motivo de conversación. Con el tiempo, este desinterés aparente de la población se volvió un verdadero dato etnográfico 


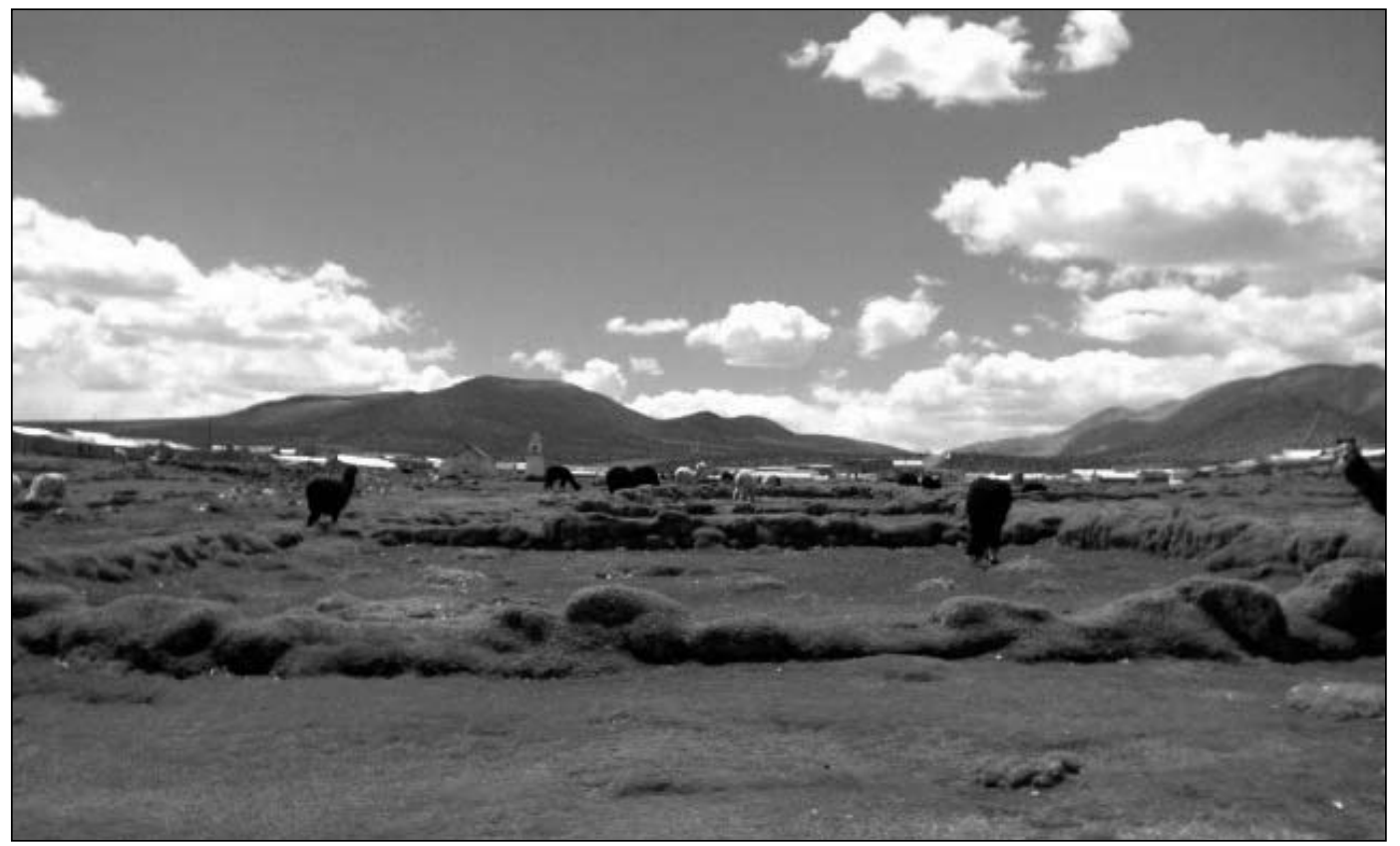

Figura 2. Vista panorámica del champial desde el este. Se perciben al fondo algunas casas comunales y el cerro Pukar Qollu.

al manifestarse como una actitud de denegación que insinuaba la existencia de otra cosa. La comprensión de dicha situación nos llevó a modificar nuestra propia postura como observadores para intentar percibir un fenómeno que no deseaba mostrarse directamente y que, no obstante, buscaba otros caminos de expresión. Así, siguiendo la actitud de los habitantes de Isluga, decidimos evacuar al champial de nuestras preguntas y referencias explícitas, para intentar comprender por qué este lugar que ocupa una posición privilegiada al interior del centro ceremonial y desprovisto de toda clase de edificaciones había llegado a ser uno de los puntales de la articulación del espacio (Figura 2).

Para beneficiar la indagación de una dimensión poco explorada por la etnografía de la región, concentremos la atención sobre el papel desempeñado por el champial. El objetivo es bien preciso, consiste en iniciar un camino para descifrar algunos de los enigmas propuestos por el singular entrecruzamiento entre los principios de centro y de vacío reunidos en este espacio. Sería imposible referirse a las múltiples relaciones que este sitio despliega con otros ejes de la configuración del centro en Isluga. El apartado ya es suficientemente largo a causa de las propias incógnitas que suscita el champial. Dejemos en consecuencia para otro análisis la puesta en relación necesaria con el resto de los articuladores del espacio del pueblo de Isluga. En especial con la nave de la iglesia, la torre campanario, la plaza de la iglesia, los calvarios y las casas ceremoniales de las familias extensas, elementos que ciertamente harán más rica y compleja la problemática. Con esta elección de método procuramos no desviar el argumento hacia el debate sobre los dualismos y triadismos estructurales que participan en la construcción de los espacios. ${ }^{23} \mathrm{La}$ ambición de este artículo es abrir más bien una posibilidad de pensar la manera en que los habitantes de Isluga tratan el problema del centro. Nos apoyamos sobre aquella "posibilidad descriptiva" reclamada por Foucault: "(...) je voudrais faire apparaître une possibilité descriptive, esquisser le domaine dont elle est susceptible, définir ses limites et son autonomie" (1969: 144). ${ }^{24}$

Un rasgo fundamental del lenguaje pictórico chino nos servirá para pensar de otra forma el lugar desempeñado

\footnotetext{
23 Estos fenómenos han sido estudiados por varios autores, entre ellos Platt (1982) y Wachtel (1990).

24 "Quisiera hacer aparecer una posibilidad descriptiva, esbozar el ámbito del cual ella es susceptible, definir sus límites y su autonomía". Traducción del autor.
} 
por el champial en la configuración del espacio. Al respecto Cheng (1991: 57) señala que "Partout, le Plein fait le visible de la structure, mais le Vide structure l'usage". ${ }^{25}$ Bajo este ángulo podría comprenderse mejor por qué un terreno vacío como el del champial puede ocupar un lugar tan central del territorio para ser una instancia de estructuración del espacio. Atentos por no fijar la atención en las cosas en sí mismas, evitamos buscar en los objetos aislados las supuestas propiedades intrínsecas. Este proceder metodológico generó una red de correspondencias insospechadas entre los distintos lugares que constituyen Isluga. Al respecto es pertinente observar las relaciones que el ch'alla churu (el nombre propio del champial) entreteje con otros actores del medio ambiente.

Existe un conjunto de relatos entre los habitantes de Isluga que asocian los vestigios de los recintos rectangulares del champial llamados churus con los corrales de los achachis (ancestros) y con la intervención del volcán Isluga (Laram Qhawani) ${ }^{26}$ sobre la faz de la tierra. En palabras de un habitante de Mauque (Isluga), el Laram Qhawani es el ch'alltiri, el que challa el mundo, el uraqui ch'alltayani (es decir, el que ch'alla la superficie de la tierra). En este caso la locución ch'alla puede ser entendida de dos maneras distintas y complementarias. Convertida en verbo la locución ch'alla subraya su acción sobre el mundo, y como sustantivo, el término ch'alla destaca el nombre de un componente físico fundamental del paisaje. Esto se debe a que el uywiri del volcán Isluga (el Laram Qhawani) crea los churus "challándolos", es decir, a través de la acción mágico-ritual característica de las libaciones ceremoniales. Paralelamente, la materia sobre la cual esta acción recae: los churus del champial, denota un elemento constitutivo de las tierras de Isluga que se benefician de la arena volcánica, llamada también challa, la cual contribuye a la fertilidad de los suelos.

Pero la figura del champial continúa enriqueciendo la comprensión de la configuración Isluga del mundo. Por

\footnotetext{
25 "Por todas partes, lo Lleno hace lo visible de la estructura, pero el Vacío estructura su uso”. Traducción del autor.

26 Otro nombre a través del cual se designa el "cuerpo" del volcán Isluga; corresponde al de Jeoq'er Qollu, término que alude a su envoltura física que es diferente del uywiri que lo anima.
}

medio de la conservación de este enigmático vacío que es propio del espacio central del pueblo, se preserva también una forma de memoria. Una memoria no sólo hecha de los restos de la intervención civilizadora de los antepasados deificados, pues se compone también de la experiencia cotidiana del encuentro entre el presentey el pasado. Encuentro privilegiado que el champial parece atesorar, y cuyas potencialidades son atestiguadas a través de la extracción de diminutos churus de champa de este preciso lugar ${ }^{27}$, los cuales son tratados como agentes rituales asociados con la fertilidad, el poder y la muerte. De este modo, los miembros de Isluga disponen cuidadosamente un pedazo del champial en la base del altar (misa) confeccionado para consagrar el cambio anual de las autoridades comunales (mallku). El conjunto de los elementos de este altar componen un sistema de artefactos rituales indispensable para que el traspaso del poder de los mallku pueda efectivamente realizarse. Dentro de este marco, la posición que ocupan los pedazos de champial en el altar expresa su inserción física y simbólica en los cimientos del poder (Figura 3).

La concepción del poder de los mallku se encuentra ligada estrechamente con la misión fundamental que éstos deben cumplir: garantizar la participación adecuada de los habitantes de Isluga en la regeneración de los seres y de las cosas; de ahí la inextricable relación entre poder y fertilidad. El testimonio de un anciano de Sitani (Isluga) registrado por Martínez (1989 [1979b]: 123) enriquece el sentido del champial en tanto fuente de fertilidad: "[antes] no había ahí champial, era tierra arenosa ch'alla ${ }^{28}$, y en ella todas las familias tenían un pequeño trozo de chacra, un churu, delimitado por las paredes de ch'ampa". La fuerza de este fragmento procede de su carácter sintético y de las diversas conexiones que establece. En primer lugar, se trata de la repartición entre todas las familias de la comunidad del derecho de uso de este restringido terreno, lo que enfatiza su importancia estratégica así como su valor simbólico. Aún hoy en día el uso del champial es comunal y ninguna familia ni sección de Isluga puede pretender su

\footnotetext{
27 Los churus de champa son pedazos de pasto enraizado en la tierra.

28 Recuérdese que el nombre propio del champial es ch'alla churu.
} 


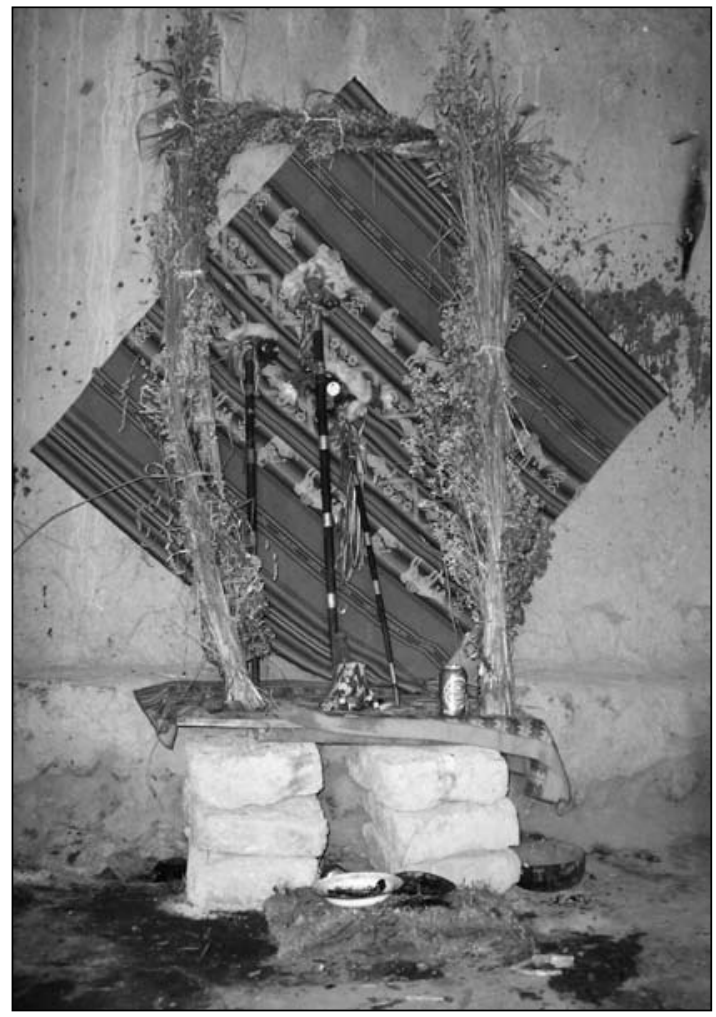

Figura 3. Altar para la ceremonia de traspaso de poder de las autoridades mallku.

propiedad absoluta. El derecho a la participación de todos los hogares y la interdicción de su posesión exclusiva recuerda la condición imperativa de la circulación y distribución del poder de los mallku. Se comprende de paso la importancia del esfuerzo de los habitantes de Isluga por mostrar este sitio como un lugar ordinario, sin características particulares, "vaciado" de identidad y desprovisto de señales de propiedad. He ahí uno de los encantos del champial que lo vuelven una creación cultural tan compleja y singular.

La referencia hecha sobre el antiguo uso agrícola del espacio ocupado por el champial añade una nueva paradoja cuya indagación podría arrojar algunas pistas complementarias. Este lugar, en tanto espacio emblemático de la domesticación de las potencias fertilizadoras del paisaje, parece conciliar la actividad agrícola de las chacras primitivas con su utilización actual como lugar de pastoreo. Por otra parte, la conjunción entre el derecho a la repartición de parcelas a todas las familias de Isluga y la superficie reducida de este lugar desaprueba el argumento de la productividad como valor principal de estas microchacras. Cabe preguntarse entonces, ¿cuál es el sentido de la participación colectiva en el cultivo de esta pequeña superficie? A este respecto, no resulta absurdo considerar la hipótesis del uso ritual de las chacras (churus), presunción a la cual Martínez también llegó apoyándose en presupuestos totalmente diferentes. ${ }^{29}$ La discusión de los detalles de la interpretación de este autor nos llevaría a un terreno incierto compuesto de conjeturas históricas que no es conveniente alimentar. Limitémonos a observar la plausibilidad de la hipótesis de este cultivo ritual a la luz de prácticas análogas en otras sociedades amerindias.

En un sentido estrictamente formal, es sugerente el caso del cultivo ceremonial realizado al interior de los templos kiva de los indios pueblo, así como el simbolismo del sipapu, un orificio central ubicado al interior de estas kivas cuyo simbolismo se asocia estrechamente a la fertilidad agrícola. ${ }^{30}$ Podría señalarse igualmente el ejemplo de los huicholes (wixaritari) del occidente de México, quienes continúan hoy en día reservando un terreno agrícola, la milpa o waxa, para el consumo de las deidades encarnadas por los cargos rituales (xukurikate). Habitualmente este terreno se localiza en los alrededores de los centros ceremoniales (tukipa). Asimismo, al interior de los templos (tuki) se encuentra un disco de piedra grabado (tepari) que normalmente se ubica en el centro del espacio ritual, enterrado debajo del lugar destinado al fuego. A este objeto (tepari) se le atribuye el poder de la regeneración de la vida; en especial durante los rituales agrícolas se le ofrenda la sangre de los animales sacrificados. ${ }^{31}$

\footnotetext{
29 Nos referimos a la interpretación que Martínez realiza de la tesis propuesta por Lévi-Strauss sobre las relaciones de transformación (al nivel de las organizaciones sociales) de las estructuras diádicas en estructuras triádicas concéntricas. Ver Lévi-Strauss (1995 [1956]: 165-191).

30 Bajo el término "indios" o "grupos pueblo" se alude a un conjunto de sociedades indígenas ligadas históricamente que poseen un corpus compartido de mitos y rituales. Los indios pueblo comparten también un espacio geográfico, el suroeste de Estados Unidos. Entre las sociedades más conocidas etnográficamente que componen este complejo geográfico y cultural están los hopi, zuñi, tewa, acoma y keresan (Parsons (1996[1939]).

31 Los huicholes de Tateikita (Jalisco) y de Colorado de la Mora (Nayarit) se refieren metafóricamente a este objeto como la "matriz del mundo" (ver
} 


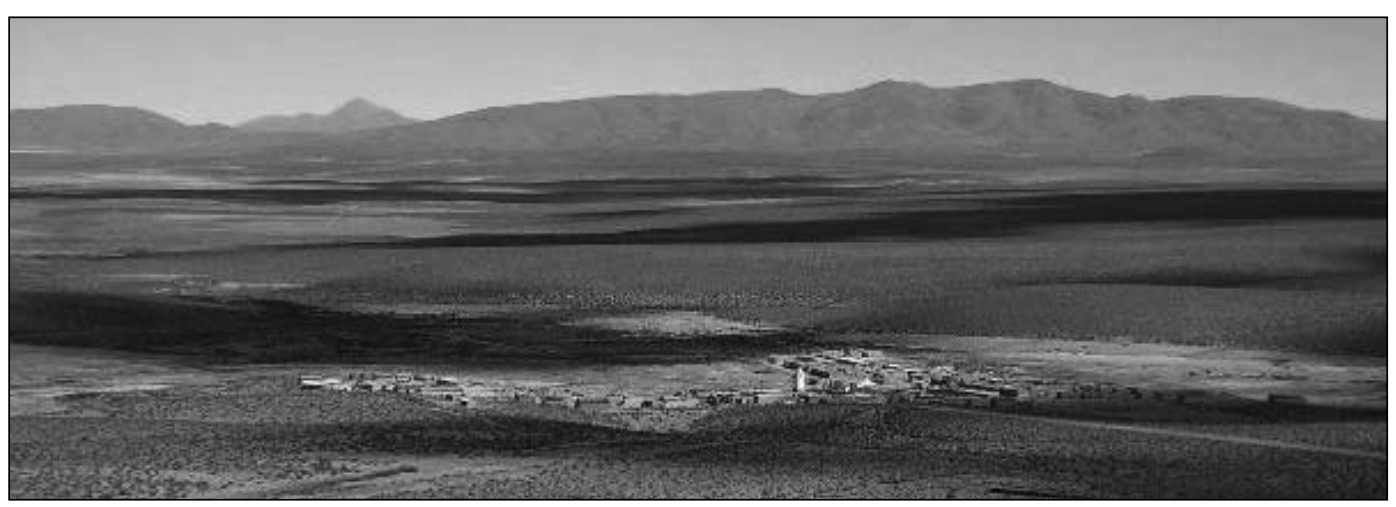

Figura 4. Vista del pueblo de Isluga desde el cerro Pukar Qollu.

En nuestro terreno, el champial en tanto centro de otro centro (pueblo de Isluga) continúa suministrando un rico material para la reflexión. A partir de la observación y descripción de la morfología del conjunto del centro ceremonial de Isluga se puede constatar sin mayor contrariedad que el champial introduce el "vacío" en el corazón mismo (chuyma) de la configuración del espacio del poblado (Figura 4).

En este nivel de la observación se constata que la peculiar característica del champial de insertarse al centro de la localidad de Isluga, la cual también ocupa una posición central en la organización del conjunto del territorio, va aparejada de otra duplicación, la que concierne al vacío. En este sentido, la importancia de las actividades rituales que deben realizarse en el pueblo de Isluga, así como la participación de este lugar como eje de la organización social y cosmológica del espacio contrasta - ante los ojos del observador externo- con su insignificante demografía. En efecto, la localidad de Isluga permanece prácticamente deshabitada durante los periodos no marcados por el calendario ritual. Si un forastero llegara a Isluga, en especial durante la temporada fría (juyphi pacha) ${ }^{32}$, no sería difícil que tuviese la impresión de visitar un pueblo fantasma, dejado por la historia y abandonado por sus habitantes. La apariencia de descuido que durante ciertos periodos ofrece el centro ceremonial de Isluga se reproduce en su

Faba 2006 y Aedo 2003). Para una visión general de los objetos rituales huicholes remitimos al clásico estudio de Lumholtz (1986 [1900]).

32 "El tiempo de las heladas", entre los meses de abril y junio. interior a través de ese espacio agreste que constituye el champial.

Se han observado hasta el momento algunas de las maneras en que los temas de la fertilidad y del poder se entrelazan para alimentar el simbolismo del centro. Sin embargo, un elemento apenas aludido, la muerte, debe ser retomado para explorar la combinación en apariencia paradojal entre el vacío y el centro. La extracción de pedazos del champial para fines rituales no se limita a la composición del altar para el cambio de las autoridades (mallku), función que relaciona a la expresión material del centro del territorio (el champial) con los fundamentos simbólicos del poder tradicional. A través de un procedimiento similar de sustracción ritual de un pedazo de champial, el inframundo (manqha pacha) ${ }^{33}$ interviene en este juego de concatenaciones. En particular, los habitantes de Isluga expresan la relación entre el mundo de los muertos y el champial a través de la disposición cuidadosa de pequeños pedazos de champa del chialla churu sobre las tumbas de las principales familias de la comunidad, las cuales se ubican en el cementerio central de Isluga. Visto desde la cima del cerro Pukar Qollu, el cementerio parece prolongar el espacio "vacío" del centro de Isluga. La operación de marcar con pequeños churu las tumbas resulta más significativa cuando se la compara con la ausencia total de este tipo de ofrendas en los cementerios secundarios de las estancias (Figura 5). Aunque la

\footnotetext{
33 Manqha pacha (el mundo de adentro/abajo). La raíz posicional manqha indica aquello que se sitúa adentro y abajo. En Isluga, en el plano geográfico frecuentemente se utiliza el término manqha para aludir a los valles de Chiapa y a las planicies costeras del occidente.
} 


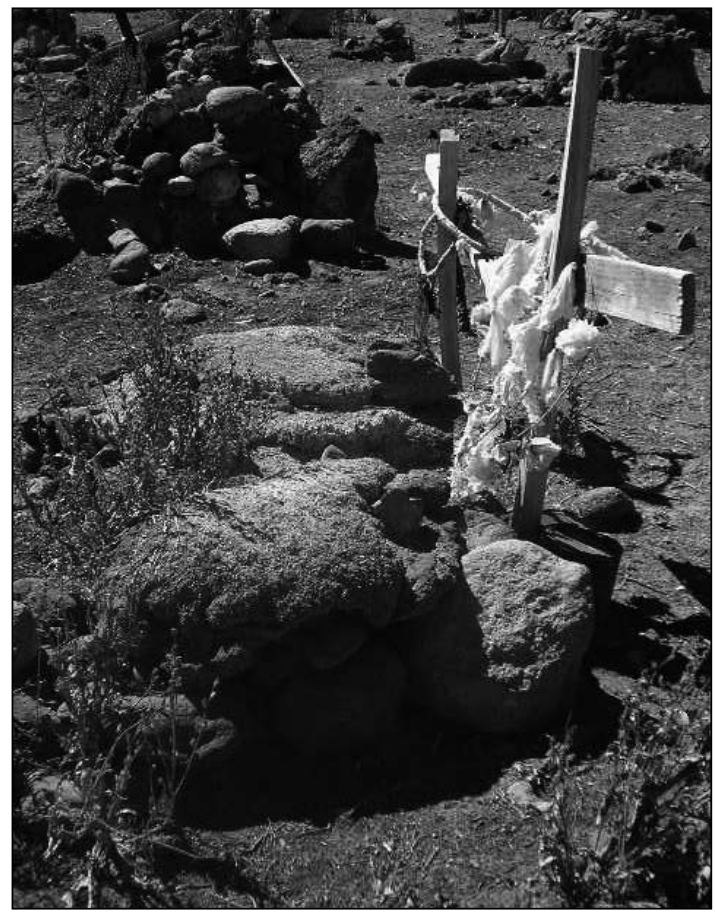

Figura 5. Pareja de tumbas con pedazos del champial.

entrada del cementerio se ubica al sureste del pueblo, la mayor parte de las tumbas está orientada hacia el este, siguiendo así la disposición general de todo el pueblo y centro ceremonial.

Se cometería un error si se desdeñara la posibilidad de observar esta singular característica de las tumbas a la luz de las torres funerarias o chullpas que se localizan en los alrededores de Sitani, lugar que forma parte de una de las 12 estancias "originales" que conforman el territorio de la comunidad de Isluga. ${ }^{34}$ La analogía se justifica en la medida en que las chullpas han representado para diversas sociedades andinas del presente $y$ del pasado un verdadero paradigma de la morada de los ancestros, cuyos despojos conforman una fuente de poder, a veces benigno, a veces indómito y nefasto. Los pedazos del champial dispuestos sobre las tumbas

34 Sitani es parte del ayllu kollana y compone la mitad manqha saya de la comunidad de Isluga. Se atribuye un valor simbólico al número 12, el cual aparece con frecuencia en los mitos y rituales para otorgar la forma definitiva a los ordenamientos del cosmos. No resulta al azar, por lo tanto, que la plaza central del pueblo se denomine tunkapan plaza, es decir el lugar donde confluyen las 12 partes del territorio ("la plaza de los 12"). del pueblo refuerzan la afinidad formal con las chullpas de Sitani (Figura 6).35

Al igual que las tumbas del cementerio del pueblo de Isluga, la mayor parte de las chullpas de Sitani se orientan cardinalmente hacia el este. Asimismo, en ambos conjuntos funerarios se observa la tendencia a agrupar los elementos (tumbas y chullpas) por pares proporcionalmente asimétricos. ${ }^{36}$ Se constata además que el cementerio del pueblo y las chullpas de Sitani comparten dos características ligadas a sus emplazamientos respectivos: la ubicación al borde de un humedal (bofedal) y la localización geográfica en el lado oriental del río Isluga.

La atención puesta en la materialización del centro del espacio Isluga llevó a explorar temas tan diversos como los de la muerte, la fertilidad, los ancestros deificados y el poder de las autoridades. Los pedazos de champial depositados sobre las tumbas y en la base del altar de las autoridades permitieron percibir el vínculo entre los difuntos, la fertilidad de los corrales y chacras primitivas del champial, el uywiri del Pukar Qollu, los antepasados (gentiles) que rondan las chullpas y los fundamentos simbólicos del poder tradicional de los mallku.

El recorrido en torno al simbolismo del champial de Isluga ha permitido también entrever la forma en que diversos elementos del espacio sin relación aparente se comunican entre sí para conformar campos semánticos que exhortan a ver el mundo de otro modo. ${ }^{37}$ Detrás

35 Las chullpas de Sitani tienen una función funeraria manifiesta y se caracterizan por estar construidas básicamente con adobe compuesto de barro, paja y arena volcánica. Estos rasgos las distinguen de otras chullpas de los Andes del norte de Chile, como aquellas de la cuenca superior del río Loa, las cuales fueron erigidas fundamentalmente con piedras y en las que - para el caso de Likan - no se han encontrado restos óseos humanos (Aldunate et al. 1981; Berenguer et al. 1984).

36 Según el registro arquitectónico de las chullpas de Isluga realizado por Ayala, sobresale la regularidad de la orientación, constituyendo "el suroeste $(55.56 \%)$ la dirección cardinal preferida, aunque varios vanos fueron dirigidos al este (33.33\%) y uno solo al noroeste (5.56\%)" (2001: 68).

37 En este sentido, las formas de apropiación Isluga del espacio responden a la declaración de principios que considera que: "La vraie philosophie est de réapprendre à voir le monde, et en ce sens une histoire racontée peut signifier le monde avec autant de 'profondeur' qu'un traité de philosophie" (Merleau-Ponty 1989: XVI). 


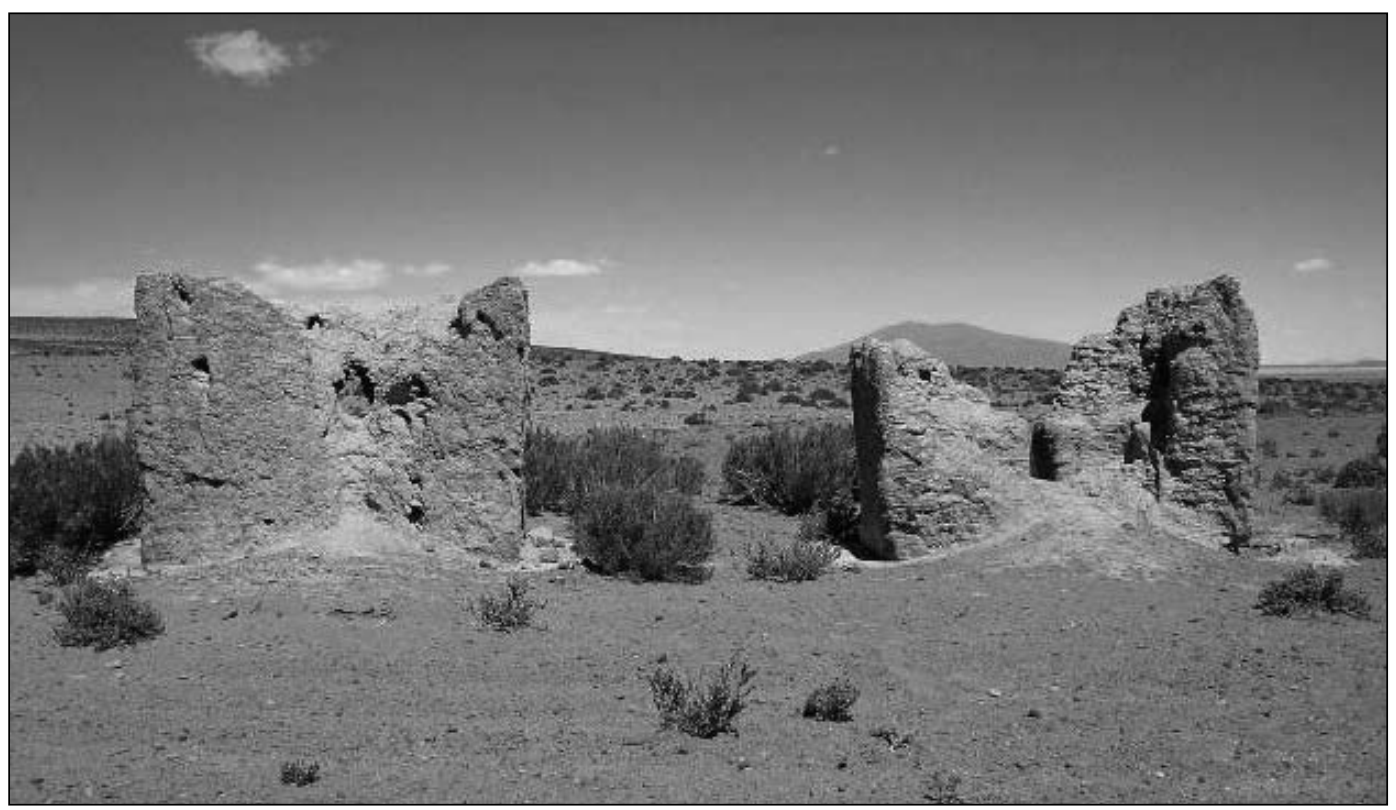

Figura 6. Pareja de chullpas, Sitani, Isluga.

de la apatía inicial en relación al champial que ilusoriamente atribuimos a los habitantes de Isluga, se vio tejer una rica red de significaciones. No obstante, más allá de la constatación de la densidad simbólica de este paisaje cultural, se vislumbraron a partir del champial algunas de las formas en que era tratado el problema fundamental del centro. Esta temática apareció asociada a la constante del vacío como centro del espacio. Al respecto debe reconocerse la importante participación que los islugueños han hecho jugar al champial como un extraordinario lugar para representar y vivenciar la integración de las nociones de centro y de vacío.

En tanto centro ritual despoblado, Isluga refleja también a un nivel socioterritorial la constante espacial del centro/ vacío. El conjunto de las edificaciones de este centro ceremonial forman la figura de un semicírculo hueco que se abre hacia el este, siguiendo de esta manera una norma de orientación de la mayor parte de las construcciones y de las acciones rituales de las sociedades andinas (Figura 7). ${ }^{38}$ En tiempos en que la sociedad

\footnotetext{
${ }^{38}$ En particular llama la atención el isomorfismo, ya notado por Martínez (1989 [1976b]: 124), entre la traza urbana en "U" del pueblo de Isluga y la forma en herradura orientada al este del plano general de los sitios Pukara documentados por Lumbreras (1974: 55-85).
}

chilena contemporánea hace de la memoria la materia de numerosos festejos con ocasión del bicentenario de la República, los islugueños nos enseñan una manera en que la memoria también puede subvertir los límites del tiempo cronológico para materializarse en un espacio vivido ${ }^{39}$, cuyo dinamismo apenas vislumbramos.

\section{* Elementos de morfología social}

En Isluga, la estancia constituye una unidad territorial básica. Una forma local para aludir a esta formación socioterritorial es la locución qutu qutu marka. La demografía de las estancias de Isluga varía de 10 a 40 familias nucleares. El término qutu qutu marka destaca un aspecto de la geografía social de Isluga que parece ser significativo para la percepción del espacio de sus habitantes, ya que describe formalmente al agrupamiento de pequeños conjuntos. La expresión qutu

\footnotetext{
39 No lejos de estos espacios de la memoria, el trabajo pionero de Halbwachs (1967: 103 y 104) señala un fenómeno compartido: “(...) la résistance permet le mieux d'apercevoir à quel point, en de tels groupes, la mémoire collective prend son point d'appui sur des images spatiales. (...) Les pierres et les matériaux ne vous résisteront pas. Mais les groupes résisteront, et, en eux, c'est à la résistance même sinon des pierres, du moins de leurs arrangements anciens que vous vous heurterez".
} 


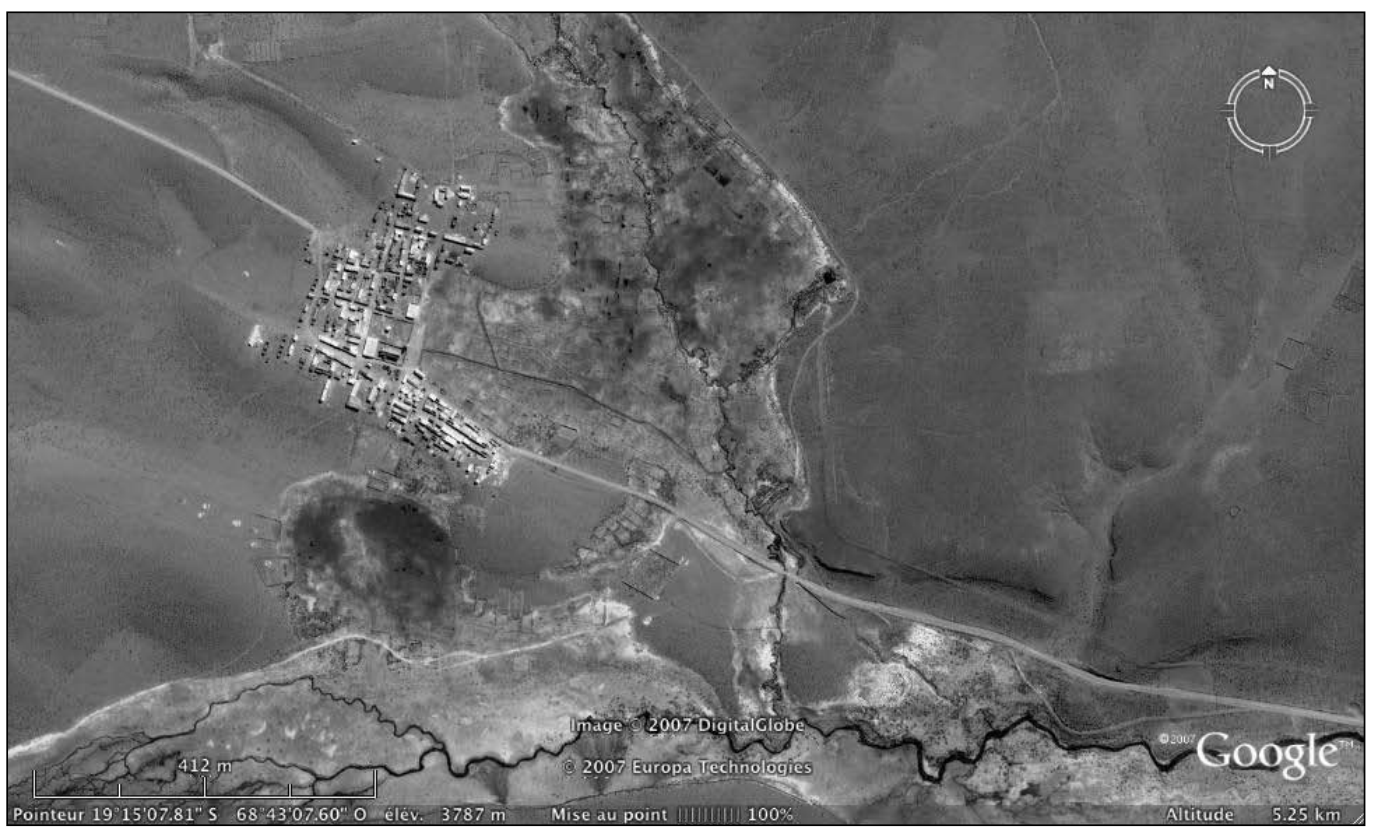

Figura 7. Isluga: Fotografía satelital adaptada de Google Earth (2007).

qutu indica literalmente la aglomeración de grupos de elementos. ${ }^{40}$ La organización del espacio en los tejidos de Isluga suministra interesantes pistas para pensar por analogía este aspecto de la organización social del espacio.

La percepción de la participación de las estancias (qutu qutu marka) en la construcción del paisaje social sigue un modelo compartido con el de los tejidos. La comparación de los principios de composición formal del espacio de los tejidos con otros ámbitos de la realidad social de los pueblos andinos no resulta una novedad. Este tipo de ejercicio metodológico ha encontrado un rico material para ser estudiado en las sociedades que habitan los Andes Centrales y Centro Sur. ${ }^{41}$

\footnotetext{
40 Según De Lucca (1983:235) el término kotu kotu quiere decir "montones juntos". Bertonio (1984 [1612]: 36) registra el verbo qutuchaña: "amontonar". Asimismo percibe entre sus colaboradores indígenas algunas referencias a una forma de organización socioespacial probablemente similar a la que caracteriza las estancias de Isluga. Esta forma es transcrita como "coto coto marka" y traducida en ausencia de equivalente por "aldea".

${ }^{41}$ Ver, por ejemplo, Cereceda (1978), Desrosier (1988), Murra (1989) y Franquemont y colaboradores (1992).
}

Realizaremos un breve paréntesis con el objeto de precisar el centro de interés que distingue esta investigación de las precedentes. Nuestra preocupación es explorar el juego de escalas que subyace a las operaciones de comprensión del mundo. Para esto consideramos que la comparación entre diversos planos de la realidad no debiera constituir solamente un medio, es decir, un procedimiento metodológico del investigador. Nuestra problemática obliga, por consiguiente, a modificar la óptica para hacer del estatus mismo de la puesta en relación analógica el objeto principal del análisis. En otras palabras, lo que nos interesa es intentar conferir toda la atención a las operaciones del pensamiento que los islugueños ponen en juego para organizar el espacio y comprender el mundo. De esta forma, lo que hemos llamado juego de escalas adquiere un matiz diferente, puesto que este fenómeno no se limita a servir como un instrumento de investigación isomorfo a los esquemas cosmológicos nativos. Ante todo, nos interesa abordar la irrupción de este fenómeno de encajamiento sucesivo del espacio-tiempo como uno de los dispositivos maestros que organizan la percepción y orientan la acción de los habitantes de Isluga.

El término churu, al que se hizo mención para hablar de los pedazos del champial y para aludir a los corrales 
y chacras de Isluga, ya fue registrado por Bertonio para referir una forma de fraccionamiento de la tierra. Así, el jesuita otorga las siguientes traducciones: "churu: pedazo o retazo de tierra, y otras cosas como paño"; "churu vel phutu suka: camellones más pequeños” (1984 [1612], II: 94). En otro registro, la idea que churu expresa se representa también en los tejidos de Isluga a través de la disposición de reglones rectangulares que se alternan por contraste de tonalidad, así como por la oposición cromática entre la iconografía que presentan y el color que rodea los motivos dentro de las cajas churos. ${ }^{42}$

Retomemos la idea de agrupamiento que es también evocada en la terminología de los textiles tradicionales. El término qutu se vincula con la percepción que los habitantes de Isluga se hacen del tipo de hábitat producido por sus estancias (qutu qutu marka). El agrupamiento de unidades domésticas (phayawi) que componen a las estancias es un rasgo del paisaje social del altiplano. El lenguaje de los tejidos parece hacer uso de dicha característica del espacio habitado para abstraer uno de sus principios por medio de un motivo iconográfico llamado precisamente qutu. Esta figura que aparece usualmente en los tejidos de Isluga se reconoce en otros lugares de los Andes Centro Sur e incluso puede ser pesquisada en varios tejidos preincaicos encontrados en el norte chileno, el Noroeste Argentino y el occidente boliviano. ${ }^{43}$

Existen elementos que llevan a pensar que la figura de qutu, la cual se compone a partir de la agregación de pequeños rectángulos, forma parte de un sistema restringido de figuras que los habitantes de Isluga codifican lingüísticamente. En este sentido, Gavilán y Ulloa (1992) registran seis motivos principales utilizados en las fajas (w'aka), estos son: killi, linko, carnero, jiwillo, salta y kutu o qutu. En palabras de las autoras estos "dibujos identificados por las tejedoras con nombres propios en

\footnotetext{
42 Los estudios de Cereceda (1978), Dransart (1988) y Gavilán y Ulloa (1992) confirman la utilización del término churu para indicar un tipo de espacio cerrado específico de los tejidos de Isluga.

43 Por ejemplo, Dransart (1988:42) informa la presencia de este motivo en tejidos de San Pedro de Atacama, Arica y cementerio de Chacance, en el Loa Medio. Asimismo refiere la presencia de qutu en textiles de Mojocoya y de Chuquisaca en Bolivia, y en los yacimientos de Doncellas, Santa Rosa de Tastil y Bilcapara en la Puna argentina.
}

las zonas de Isluga y Cariquima constituyen unidades básicas" (Gavilán y Ulloa 1992: 125).

A partir del diseño qutu las tejedoras de Isluga codifican en términos visuales la acción de agrupar distintas colectividades dentro de un mismo espacio textil. La simplicidad técnica y la popularidad de este motivo hacen que qutu sea uno de los primeros diseños en ser transmitidos en el aprendizaje de las tejedoras jóvenes. De esta manera, se familiariza en la práctica cotidiana uno de los principios básicos de la geografía social de los habitantes de Isluga: la agrupación de colectivos que conservando sus singularidades se integran sin fusionarse dentro de conjuntos socioespaciales más amplios y heterogéneos.

Es importante subrayar que cuando se agrega a qutu qutu el término marka, se hace referencia al agrupamiento de unidades domésticas y no a la reunión de individuos aislados. ${ }^{44}$ En otro nivel de la organización social, se observa que la noción de qutu es una vez más requerida, esta vez para denotar la existencia de agrupamientos de cooperación mutua. Un tipo de formación colectiva poco formalizada, cuya estructura y duración obedece a la situación social que se presenta en la práctica cotidiana.

Las redes de los habitantes de Isluga forman grupos rituales y de trabajo que tienden a ser obligatorios, pero además de estos grupos existen numerosas organizaciones completamente voluntarias dedicadas a una o varias tareas específicas, que son a veces llamadas simplemente qutu o tama. ${ }^{45}$ La fortaleza de este tipo

\footnotetext{
44 Entendemos a los hogares como "grupos domésticos" en el sentido aplicado por Segalen (1988: 15-16), es decir, como un conjunto de personas que comparten el mismo techo.

45 En este contexto, el sentido del término qutu remarca la existencia de una colectividad de seres que comparten intereses. Por otra parte, la palabra tama refuerza la idea de la formación de un cuerpo colectivo de individuos. Dentro del campo semántico del pastoreo, tama aparece con frecuencia para indicar rebaño. De la misma manera Bertonio (1984 [1616]:334) indica que tama significa "manada de hombres y animales", y De Lucca (1983:398) registra para este término los siguientes significados: "conjunto de personas o animales. Caravana, tropa de viajeros. Conjunto, reunión de varias cosas. Junta, reunión de personas. Rebaño, manada, tropa".
} 
de organizaciones reside en su adaptabilidad, ellas atraviesan todas las demás categorías estructurales y están basadas principalmente en los fines funcionales específicos hacia los cuales están orientadas. Se encuentra, por ejemplo, este tipo de agrupamientos para la construcción de casas, para diversas formas de trabajo agrícola, para hacer música, para fabricar ladrillos, para erigir y mantener los oratorios ("calvarios" o silos), para vender alimentos y otras mercancías en la fiesta de La Tirana, y realmente para una docena de otras tareas. ${ }^{46}$ La lealtad hacia estos agrupamientos de cooperación mutua (qutu o tama) es un valor mayor de los habitantes de Isluga. Desde cierto punto de vista, toda la vida social en Isluga puede ser considerada como un conjunto de grupos de este tipo, tanto formales como voluntarios.

La inmensa mayoría de las estancias posee también pequeños caseríos satélites esparcidos a través de las zonas ecológicas. Estas microunidades territoriales son habitadas temporalmente. Para este efecto se construye un tipo de casa secundaria llamada jant'a. La ocupación intermitente de estos lugares es precisamente una de sus características principales; lo que no quiere decir que estos caseríos sean abandonados, ellos son solamente dejados en descanso. Esta parte de la geografía social de los habitantes de Isluga se designa bajo los términos de uta uta y utjäwi. ${ }^{47}$

Las casas uta del altiplano se dividen habitualmente en cocinas (phayawi) ${ }^{48}$, en principio una cocina por familia nuclear. La agrupación de cocinas conforma la unidad de parentesco básica desde el punto de vista de todas las instituciones sociales superiores. Asimismo,

${ }^{46}$ La fiesta de La Tirana es una de las más importantes celebraciones religiosas del Norte Grande de Chile. Tiene lugar durante el mes de julio en el pueblo de La Tirana, ubicado en el corazón de la Pampa del Tamarugal. Hacia este pequeño pueblo de alrededor de 560 habitantes se dirigen más de 150.000 personas entre peregrinos, danzantes, comerciantes y turistas.

47 El término uta uta se construye a partir de la duplicación de la palabra uta que quiere decir casa. Según algunos habitantes de Isluga, el término utjäwi significa igualmente hogar.

${ }^{48}$ Phayawi en sentido estricto designa al lugar destinado a la preparación de los alimentos. Según England (2001: 106) phaya.ña quiere decir “cocinar" y phay.xaya.ña "cocinar para alguien". Por otra parte, Bertonio (1984 [1616]: 148) transcribe la acción de cocinar como phaafina uta. la cocina constituye uno de los lugares fundamentales donde se tejen las redes de solidaridad y se refuerzan los lazos de parentesco. Bajo este aspecto, la cocina en Isluga comporta (a nivel socioeconómico) una unidad de administración de recursos productivos que administra un presupuesto y que establece constantemente estrategias de vida congruentes con las circunstancias del momento. La "cocina" también debe enviar idealmente un trabajador para reparar los calvarios (oratorios) de los alrededores ${ }^{49}$ y debe -entre otras cosas-ocuparse de un rebaño compuesto de llamas y alpacas, cuyo futuro se encuentra ligado tradicionalmente al devenir de esta misma unidad doméstica. A través de la "cocina" los individuos adquieren derechos y obligaciones dentro de sus contextos sociales de interacción. Es por esta razón que se puede argumentar que no es el individuo sino esta unidad doméstica, en tanto institución socioespacial, la que participa en el establecimiento de las conexiones de base para la construcción de las relaciones rituales y políticas que conforman la localidad de Isluga.

\section{- El espíritu del lugar: Una apuesta de SENTIDO}

Las relaciones que mantienen entre sí las agrupaciones de unidades domésticas (phayawi) impactan la dinámica interna de los hogares contemporáneos de Isluga. Dichas interrelaciones alimentan igualmente un vigoroso fenómeno de construcción de redes socioterritoriales. El alcance espacial de estas redes comprende diferentes zonas ecológicas que en un primer momento podría evocar el modelo de la complementariedad vertical a la escala más pequeña de los pueblos de reducción. ${ }^{50} \mathrm{Sin}$ embargo, esta semejanza es solamente formal porque

\footnotetext{
49 Los silos o calvarios son pequeños oratorios de alrededor de $1 \mathrm{~m}$ de alto que poseen un nicho, el cual por regla general se orienta hacia el este. Estas edificaciones portan habitualmente una cruz sobre el techo, y se caracterizan por establecer entre ellas líneas rectas bastante precisas que cruzan todo el territorio de Isluga.

50 Dentro de este tipo de organización socioespacial en "archipiélago" (Murra 1975) algunas zonas explotadas por el mismo grupo social son muy distantes, de hasta 10 días de marcha, lo que implica: ya sea la migración estacional de la población (Brush 1976; Platt 1982; Wachtel 1990), o bien, el establecimiento de colonias permanentes como las descritas por Murra.
} 
dicho fenómeno descubre más bien la existencia de una red de microrredes de solidaridad que desborda la esfera rural para ir a reproducirse en diversos contextos del mundo urbano.

El eje residencial de base en el altiplano de Isluga es la casa familiar o uta que, en términos de parentesco, puede albergar grupos que van de la familia nuclear simple a la familia extensa de tres generaciones. Uno de los términos para designar a la familia, utanquirinaca, se construye a partir del lexema uta (casa). Esto deja traslucir la importancia de la residencia, y por tanto, del espacio doméstico compartido como uno de los factores constitutivos de los lazos de parentesco. El término utanquirinaca es empleado indiferentemente para significar una relación de parentesco y un lazo social localizado; asimismo la expresión emparentada uta jac'a denota una relación de familiaridad entre personas que frecuentan los mismos lugares. ${ }^{51}$

A lo largo de estas páginas se transitaron diferentes escalas de observación que permitieron examinar algunos de los intersticios de "la producción de una localidad" (para retomar el término utilizado por Appadurai [2005]). Este fenómeno se ha convertido en un tema capital de la investigación antropológica contemporá- nea. Los contextos de vecindad que conforman Isluga y que le otorgan toda su actualidad confluyen en hacer de este "lugar" el pivote sobre el cual giran y se tejen los lazos sociales que trascienden sus propios límites espaciales. Dicha percepción general de la localidad de Isluga es regularmente sometida a prueba por medio de la experiencia de sus habitantes y resulta un verdadero esquema de la práctica. ${ }^{52}$ De esta manera, los islugueños enfrentan hoy día nuevas situaciones sociales que los impulsan a salir de esta localidad para poder en definitiva allí permanecer. Sobre esta paradoja aparente se anuda una nueva lógica de arraigamiento, la que se expresa por el ir y venir de sus miembros hacia otros terrenos de "colonización" tanto rurales como urbanos. He aquí una de las contribuciones que los islugueños hacen a propósito del "espíritu" de los lugares, del cual el poeta Parra constataba que: "Todo y cada cosa tiene su singular y plácida leyenda. Todo está en su lugar, todo está igual, isólo que el tiempo lo ha borrado todo como una blanca tempestad de arena!" (1997 [1954]).

Agradecimientos A la memoria de Gabriel Martínez. Agradecemos a los lectores del manuscrito de este trabajo por sus sugestivas y útiles observaciones. Las fotografías 1 a 6 fueron tomadas por P. Faba y el autor.

\section{* RefERENCIAs citadAs}

AberCrombie, T. A., 1990. Ethnogenèse et domination coloniale. Journal de la Société des Américanistes LXXVI: 95-104.

1998. Pathways of memory and power. Ethnography and History among an Andean people. The University of Wisconsin Press, Madison.

AEDO, A., 2003. Flores de lujuria e influjos siniestros: Fuentes nocturnas del simbolismo huichol del cuerpo humano. Anales de Antropología de la Universidad Nacional Autónoma de México 37 : 173-204.

Aldunate, C., J. Berenguer y V. Castro, 1981 [1979]. La función de las chullpa en Likan. Actas del VIII Congreso de Arqueología Chilena, pp. 129-174. Ediciones Kultrun, Santiago.

\footnotetext{
${ }^{51}$ Una traducción aproximada apoyada sobre algunas exégesis de los islugueños podría ser "el corresidente de alguien".
}

Appadurai, A., 2005 [1996]. Après le colonialisme. Les conséquences culturelles de la globalisation. Editions Payot, París.

AyalA, P., 2001. Estudio arquitectónico de las chullpas de adobe de Isluga (I región), período Intermedio Tardío. Boletín de la Sociedad Chilena de Arqueología 32: 66-76.

BENGOA, J., 2004. Los aymaras del norte de Chile. En La memoria olvidada. Historia de los pueblos indígenas de Chile, J. Bengoa (Ed.), pp. 95-151. Publicaciones del Bicentenario, Santiago.

Berenguer, J., C. Aldunate y V. Castro, 1984. Orientación orográfica de las chullpa en Likan: La importancia de los cerros en la fase Toconce. Simposio Culturas Atacameñas, $44^{\text {avo }}$ Congreso Internacional de Americanistas, Manchester. Universidad del Norte, Antofagasta.

\footnotetext{
52 Para el concepto de esquema de la práctica ver el tratamiento efectuado por Descola (2005: 135-162).
} 
Bertonio, L., 1984 [1612]. Vocabulario de la lengua aymara. Ediciones Ceres, Cochabamba.

Boute, V., 2003. Une tradition disputée: Enjeux identitaires dans une communauté des Andes boliviennes. Journal de la Société des Américanistes 89 (2): 125-148.

BRIGGS, L., 1975. Structure of the substantive system. En Aymara ar yatiqanataki (to learn Aymara), vol. 3. M. Hardman, J. Vásquez y J. Yapita (Eds.), cap. VIII. University Microfilms, Ann Arbor.

2001 [1988]. Estructura del sistema nominal. En Aymara: Compendio de estructura fonológica y gramatical, M. Hardman, J. Vásquez y J. Yapita (Eds.), cap. VIII. Instituto de Lengua y Cultura Aymara (ILCA), La Paz.

BRUSH, S. B., 1976. Man's use of an Andean ecosystem. Human Ecology $4(2): 147-166$.

Cereceda, V., 1978. Sémiologie des tissus andins: Les talegas d'Isluga. Annales. Economie, sociétés, civilisations 33 (5-6): 1017-1035.

Cheng, F., 1991. Vide et plein. Le langage pictural chinois. Editions du Seuil, París.

De LuCCA, M., 1983. Diccionario aymara-castellano/castellano-aymara. Comisión de Alfabetización y Literatura en Aymara, La Paz.

Descola, P., 2005. Par-delà nature et culture. Gallimard, París.

DesRosiers, S., 1988. Les techniques de tissage ont-elles sens? Un mode de lecture des tissus andins. Techniques et Culture 12: 21-56.

Dransart, P., 1988. Continuidad y cambio en la producción textil tradicional aymara. Hombre y desierto. Una perspectiva cultural 2 (2): 41-57.

Durston, A. y J. Hidalgo. 2004 [1999]. La presencia andina en los valles de Arica, siglos XVI-XVIII: Casos de regeneración colonial de estructuras archipielágicas. Historia andina en Chile, J. Hidalgo (Ed.), pp. 479-506. Editorial Universitaria, Santiago.

England, N. C., 1975. Verbal derivational suffixes. En Aymara ar yatiqanataki (to learn aymara), vol. 3. M. J. Hardman, J. Vásquez y J. Yapita (Eds.), cap. VI. University Microfilms, Ann Arbor.

2001. Sufijos verbales derivacionales. En Aymara: Compendio de estructura fonológica y gramatical, M. Hardman, J. Vásquez y J. Yapita (Eds.), cap. VI. Instituto de Lengua y Cultura Aymara (ILCA), La Paz.

FABA, P., 2006. La matriz del mundo. El tepari huichol y el sipapu de los indios pueblo. En Las vías del noroeste I: Una macrorregión indígena americana, C. Bonfiglioli, A. Gutiérrez y M. E. Olavarría (Eds.), pp. 191-206. Instituto de Investigaciones Antropológicas, Universidad Nacional Autónoma de México, México D. F.

Foucault, M., 1969. L'Archéologie du savoir. Gallimard, París.

Franquemont, E., C. Franquemont y B. J. Isbell, 1992. Awaq ñawin: El ojo del tejedor. La práctica de la cultura en el tejido. Revista Andina 10 (1): 47-80.

GAVILÁn, V. y L. UlloA, 1992. Proposiciones metodológicas para el estudio de los tejidos andinos. Revista Andina 10 (1): 107-134.

Gundermann, H., 1984. Ganadería aymara, ecología y forraje: Evaluación regional de una actividad productiva andina. Chungara 12: 99-124.

Halbwachs, M., 1967 [1950]. La mémoire collective. Les Presses Universitaires de France, París.

Hardman. M. J., 2001. Aymara. Lincom Europa, Munchen.

HaRRIS, O., 2000. To make the earth bear fruit: Ethnographic essays on fertility, work and gender in Highland Bolivia. Institute of Latin American Studies, University of London, Londres.

LÉvI-Strauss, C., 1995 [1956]. ¿Existen las organizaciones dualistas? En Antropología estructural, pp. 165-191. Ediciones Paidós, Barcelona.

Lumbreras, L., 1974. Los orígenes de la civilización en el Perú. Editorial Milla Batres, Lima.

Lumholtz, C., 1986 [1900]. El arte simbólico de los huicholes. En El arte simbólico y decorativo de los huicholes, L. Lumholtz (Ed.), pp. 27-322. Instituto Nacional Indigenista, México D. F.

Marcus, G. E., 1998. Ethnography through thick and thin. Princeton University Press, Princeton.

2002. Au-delà de Malinowski et après "writing culture": A propos du futur de l'anthropologie culturelle et du malaise de l'ethnographie. Ethnographiques.org a http://www.ethnographiques.org

Martin, L., L. T. Briggs y N. C. England, 2001 [1988]. Visión panorámica de la estructura de la lengua aymara. En Aymara: Compendio de estructura fonológica y gramatical, M. Hardman, J. Vásquez y J. Yapita (Eds.), cap. II. Instituto de Lengua y Cultura Aymara (ILCA), La Paz.

Martínez, G., 1989 [1976a]. El sistema de los uywiris en Isluga. En Espacio y pensamiento. I. Andes meridionales, G. Martínez (Ed.), pp. 13-107. Hisbol, La Paz. 
1989 [1976b]. Estructuras binarias y terciarias en pueblo Isluga. En Espacioy pensamiento. I.Andes meridionales, G. Martínez (Ed.), pp. 109-148. Hisbol, La Paz.

Medvinski, D., 1977. Las fajas de Isluga. Tesis de Licenciatura en Diseño. Escuela de Diseño, Universidad Católica de Chile, Santiago.

Merleau-Ponty, M., 1989 [1945]. Phénoménologie de la perception. Gallimard, París.

MurRa, J., 1975. Formaciones económicas y políticas del mundo andino. Instituto de Estudios Peruanos, Lima.

1989. Las funciones del tejido andino en diversos contextos sociales políticos. En Arte mayor de los Andes, pp. 9-19. Museo Chileno de Arte Precolombino, Santiago.

Núñez, E., P. Araya yJ. Salinas, 1988. Plan de manejo. Parque Nacional Volcán Isluga. Documento de trabajo 100. Ministerio de Agricultura de Chile, Corporación Nacional Forestal, Tarapacá.

Parra, N., 1997 [1954]. Hay un día feliz. En Poemas y antipoemas. Editorial Cátedra, Madrid.

Parsons, E. C., 1996 [1939]. Pueblo indian religion. University of Chicago Press, Chicago.

PlatT, T., 1982. Le rôle de l'ayllu dans la reproduction du système marchand simple dans le nord de Potosí. En De l'empreinte à l'emprise: Identités andines et logiques paysannes, L. T. Briggs, L. Chana y T. Platt (Eds.), pp. 30-89. Presses Universitaires de France e Institut Universitaire d'Études du Développement, París y Genève.

RIVIÈRE, G., 1982. Sabaya:Structures socio-économiques et représentations symboliques dans le Carangas (Bolivie). École des Hautes Etudes en Sciences Sociales, París.

Segalen, M., 1988. Sociologie de la famille. Armand Colin, París.

TORERO, A., 2002. Idiomas de los Andes. Lingüística e historia. Instituto Francés de Estudios Andinos (IFEA), Lima.

Urton, G., 1993. Contesting the past in the Peruvian Andes. En Mémoire de la tradition, A. Becquelin, A. Moliné y D. Dehouve (Eds.), pp. 107-147. Université Paris X, Nanterre, París.

VAn Kessel, J., 1992 [1980]. Holocausto al progreso: Los aymara de Tarapacá. Hisbol, La Paz.

1996. Los aymara contemporáneos de Chile. En Culturas de Chile. Etnografía, J. Hidalgo, V. Schiappacasse, C. Aldunate y P. Mege (Eds.), pp. 47-68. Editorial Andrés Bello, Santiago.

2001. El ritual mortuorio de los aymara de Tarapacá como vivencia y crianza de la vida. Chungara 33 (2): 221-234.

WACHTEL, N., 1990. Le retourdes ancêtres. Les indiens Urus de Bolivie XX-XVI siècle. Essai d'histoire régressive. Editions Gallimard, París. 